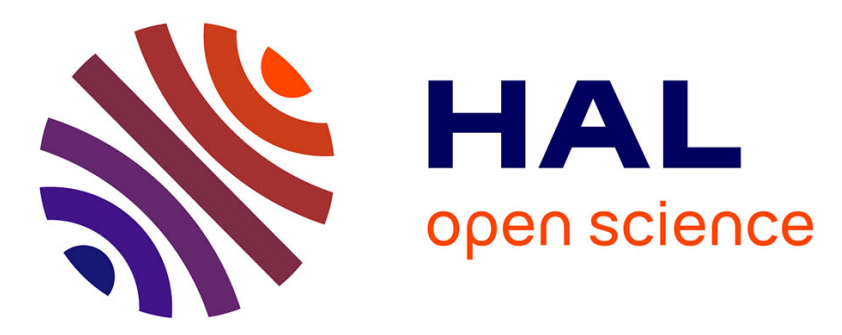

\title{
Genetic variability of transcript abundance in pig skeletal muscle at slaughter: Relationships with meat quality traits
}

P. Cherel, Frédéric Herault, Annie Vincent, Pascale Le Roy, Marie Damon

\section{- To cite this version:}

P. Cherel, Frédéric Herault, Annie Vincent, Pascale Le Roy, Marie Damon. Genetic variability of transcript abundance in pig skeletal muscle at slaughter: Relationships with meat quality traits. Journal of Animal Science, 2012, 90 (3), pp.699-708. 10.2527/jas.2011-4198 . hal-01205135

\section{HAL Id: hal-01205135 \\ https://hal.science/hal-01205135}

Submitted on 29 May 2020

HAL is a multi-disciplinary open access archive for the deposit and dissemination of scientific research documents, whether they are published or not. The documents may come from teaching and research institutions in France or abroad, or from public or private research centers.
L'archive ouverte pluridisciplinaire $\mathbf{H A L}$, est destinée au dépôt et à la diffusion de documents scientifiques de niveau recherche, publiés ou non, émanant des établissements d'enseignement et de recherche français ou étrangers, des laboratoires publics ou privés. 


\section{JOURNAL OF ANIMAL SCIENCE}

The Premier Journal and Leading Source of New Knowledge and Perspective in Animal Science

\section{Genetic variability of transcript abundance in pig skeletal muscle at slaughter: Relationships with meat quality traits \\ P. Cherel, F. Herault, A. Vincent, P. Le Roy and M. Damon}

J ANIM SCI 2012, 90:699-708.

doi: 10.2527/jas.2011-4198 originally published online October 7, 2011

The online version of this article, along with updated information and services, is located on the World Wide Web at:

http://www.journalofanimalscience.org/content/90/3/699 


\title{
Genetic variability of transcript abundance in pig skeletal muscle at slaughter: Relationships with meat quality traits ${ }^{1}$
}

\author{
P. Cherel, ${ }^{*}$ F. Herault, $\dagger$ A. Vincent,$\ddagger \S$ P. Le Roy, $\dagger$ and M. Damon $\ddagger \S^{2}$ \\ *Hendrix Genetics RTC, F-45808 St. Jean de Braye, France; †INRA, UMR0598 Génétique Animale, \\ F-35042 Rennes, France; †INRA, UMR 1079 SENAH, F-35590 Saint Gilles, France; \\ and $§$ Agrocampus Ouest, UMR1079 SENAH, F-35000 Rennes, France
}

\begin{abstract}
A family structured population of 325 pigs (females and barrows) was produced as an intercross between 2 commercial sire lines and was subjected to a systematic transcriptome analysis of LM samples obtained shortly after slaughter. Additionally, measurements of meat quality traits of fresh and cooked loin were gathered from the same animals. The transcriptome analysis was achieved by microarray hybridization, using a custom repertoire of 15,000 6mer DNA probes targeting transcripts expressed in growing pig skeletal muscle. These data allowed us to estimate the heritability of expression abundance for each of the quantified RNA species. The abundance of 9,765 RNA was estimated as heritable with a false discovery rate of $5 \%$, from which 1,174 were deemed as highly heritable $\left(\mathrm{h}^{2}>0.50\right)$. We also observed a large number of transcripts whose LM expression abundance is genetically correlated with 4 meat quality traits: the loin $\mathrm{pH}$ measured at 45 min postmortem (pH45), 253 transcripts; the loin cooking loss (CL), 134 transcripts; the cooked loin shear force $(\mathrm{SFc}), 184$ transcripts; and the loin color redness $\left(\mathrm{a}^{*}\right)$ value, 190 transcripts. Heritable and meat quality genetically correlated transcripts showed an over-representation of biological processes involved
\end{abstract}

in the induction of apoptosis (genetically correlated with CL), complement activation (genetically correlated with $\mathrm{SFc}$ ), glucose metabolism (genetically correlated with $\mathrm{a}^{*}$ ), and cation channel activity (genetically correlated with $\mathrm{pH} 45)$. Overall, the biological functions highlighted in the highly heritable transcripts and the lack of transcript that would be genetically correlated with LM glycolytic potential suggest that the genetic variability of the LM postmortem transcriptome is focused on muscle tissue response to postmortem ischemia and reflects more distantly the antemortem muscle physiology. Because of the contrasting distributions of the genetic correlations between LM RNA concentrations and the different meat quality traits studied, indirect selection strategies of meat quality traits based on measurements of selected LM RNA species could be only proposed for a subset of the analyzed meat characteristics (pH45, SFc, a*, CL). A substantial improvement in the efficiency of selection for these meat quality traits could result from measuring muscle RNA concentrations on selection candidates, if the same genetic parameters can be verified using in vivo-sampled muscles.

Key words: gene expression, indirect selection, loin meat quality, longissimus muscle, Sus scrofa, transcriptome analysis

\section{INTRODUCTION}

\footnotetext{
${ }^{1}$ This work was carried out with financial support from the ANRAgence Nationale de la Recherche-The French National Research Agency under the Programme National de Recherche en Alimentation, project ARN-PNRA-2006-25, GENMASCQ. The authors thank the staff from the Orleans Viandes abattoir, Fleury-Les-Aubrais, France, for their assistance in tracking carcasses and primary cuts, and J. Glénisson, L. Letelu, and J. Pires (Hendrix Genetics RTC, St. Jean de Braye, France), and M. Fillaut (INRA, UMR 1079 SENAH, Saint Gilles, France) for their assistance in the meat quality measurements.

${ }^{2}$ Corresponding author: Marie.Damon@rennes.inra.fr

Received April 22, 2011.

Accepted October 5, 2011.
}

Quantification of each of the RNA species found in animal cells or transcriptome analysis developed as a follow-up of genome sequencing and array technology. Transcriptome analysis initially allowed an in-depth biological description of cells or tissues that were exposed to well-defined treatments, using differential expression experiments with a limited number of samples. Further improvements in technology standardization and throughput now allow for a large number of samples to be reliably processed. Population-scale transcriptome analysis can, therefore, be used to assess the full extent 
of the variation in transcript concentrations in a given cell type or tissue among individuals in a population.

Variations in transcript abundance can drive or accompany variations in livestock production phenotypes, as mediating responses to environmental challenges or the translation of genetic variability. Meat qualitative traits are contributed by the physiology of corresponding skeletal muscles, from development (Wimmers et al., 2007) until conversion from muscle to meat (Davoli and Braglia, 2007; Ponsuksili et al., 2008). Transcriptome analysis of skeletal muscle thus has the potential to uncover variations in the abundance of selected transcripts, which could be seen and used as intermediate outcomes of the genetic variation that contributes to meat quality traits. Indirect selection strategies based on these intermediate molecular phenotypes might prove valuable for the genetic improvement of meat quality traits. Opportunities for using those molecular phenotypes in breeding applications ultimately depends on the genetic parameters for these traits, defined as skeletal muscle RNA concentrations, heritabilities $\left(\mathbf{h}^{2}\right)$, and genetic correlations $\left(\mathbf{r}_{\mathrm{G}}\right)$ with meat quality traits of economic value. Here, we report a population-scale analysis of transcript abundance in pig skeletal muscle, which enabled the estimation of genetic parameters for these molecular phenotypes.

\section{MATERIALS AND METHODS}

Procedures and slaughtering facilities were approved by the French Veterinary Services.

\section{Experimental Population}

The 325 pigs (females and barrows) used in the gene expression analyses are part of a larger $\mathrm{F}_{2}$ resource population of 1,000 animals which was setup within the framework of a QTL detection program. These animals were produced as a second generation intercross between 2 commercial sire lines (FH016, Pietrain type line, and FH019, synthetic line from Hampshire, Duroc, and Large-White founders, France-Hybrides, St Jean de Braye, France).
The 325 animals considered for LM transcriptome analysis were produced as 4 half-sib families, using $4 \mathrm{~F}_{1}$ males and $15 \mathrm{~F}_{1}$ females, where each $\mathrm{F}_{1}$ male was mated with the same group of 3 to 4 full-sib $\mathrm{F}_{1}$ females for 2 to 3 successive litters, thus purposely generating largesize full-sib families. All $\mathrm{F}_{2}$ animals were genotyped as homozygous wild type genotypes $\mathrm{NN}$ and $\mathrm{rn}+\mathrm{rn}+$ with regard to the HAL and $\mathrm{RN}$ loci, respectively (Otsu et al., 1992; Milan et al., 2000).

All $\mathrm{F}_{2}$ animals were raised on the same farm and slaughtered in the same abattoir. All pigs were killed at $110 \mathrm{~kg}$ of BW according to standard procedures for commercial slaughtering (Orleans Viandes, Fleury-lesAubrais, France). Half-carcasses were chilled at $-12^{\circ} \mathrm{C}$ for $4 \mathrm{~h}$ postmortem, then stored at $3^{\circ} \mathrm{C}$, and cut at 24 $\mathrm{h}$ postmortem.

\section{Meat Quality Measurements}

Loin meat quality measurements are briefly described because they have been already detailed previously (Laville et al., 2007). The summary statistics of the meat quality traits as recorded in the whole resource population are provided in Table 1.

Loin Processing and Measurements. The loins were sliced at $30 \mathrm{~h}$ postmortem, chops were stored at $4^{\circ} \mathrm{C}$ for $2 \mathrm{~d}$, then grilled in a dry oven at $240^{\circ} \mathrm{C}$ for 30 min. Drip loss (DL) was calculated as $100 \times(1$ - weight after storage/weight before storage). Cooking loss (CL) of the LM was calculated as $100 \times(1-$ weight after cooking/weight after storage).

Warner-Bratzler Shear Force Measurements. For both the raw (SFr) and the cooked (SFc) meat shear force measurements, 10 cylinders of $1 \mathrm{~cm}$ in diameter were sheared in a Warner-Bratzler cell. The maximal force recorded during shearing (at rupture time) was used as the cylinder shear force value and expressed in Newtons.

Loin Color Components and $\mathrm{pH}$. Indicators of lightness $\left(\mathrm{L}^{*}\right)$, redness $\left(\mathrm{a}^{*}\right)$, and yellowness $\left(\mathrm{b}^{*}\right)$ were recorded from each rib eye surface within $2 \mathrm{~h}$ after loin slicing.

The $\mathrm{pH}$ at $45 \mathrm{~min}$ in $\mathrm{LM}$ ( $\mathbf{p H} 45)$ was measured in a 1:10 (wt/wt) dispersion of LM in a $5 \mathrm{mM}$ sodium io-

Table 1. Summary statistics for loin meat quality traits ${ }^{1}$

\begin{tabular}{lllrrrc}
\hline \hline Loin quality trait & Abbreviation & Unit & $\mathrm{n}$ & $\mu$ & \multicolumn{1}{c}{$\sigma$} & Range \\
\hline $\mathrm{pH} \mathrm{45-min}$ & $\mathrm{pH} 45$ & $\mathrm{pH}$ unit & 840 & 6.55 & 0.18 & 5.45 to 7.40 \\
pH 24-h & $\mathrm{pH} 24$ & $\mathrm{pH} \mathrm{unit}$ & 1,023 & 5.71 & 0.20 & 5.37 to 6.73 \\
Glycolytic potential & $\mathrm{GP}$ & $\mu \mathrm{mol} / \mathrm{g}$ & 805 & 159.40 & 24.97 & 70.30 to 276.80 \\
Intramuscular fat & $\mathrm{IMF}$ & $\mathrm{g} / 100 \mathrm{~g}$ & 804 & 2.24 & 0.66 & 0.79 to 4.92 \\
Color CIE L* & $\mathrm{L}^{*}$ & $\mathrm{CIE} \mathrm{u}$ & 852 & 49.63 & 3.05 & 37.92 to 57.54 \\
Color CIE a* & $\mathrm{a}^{*}$ & $\mathrm{CIE} \mathrm{u}$ & 852 & 7.86 & 1.22 & 4.64 to 13.00 \\
Color CIE b* & $\mathrm{b}^{*}$ & $\mathrm{CIE} \mathrm{u}$ & 852 & 5.12 & 1.30 & 0.48 to 9.30 \\
Shear force, cooked & $\mathrm{SFc}$ & $\mathrm{N}$ & 753 & 33.65 & 1.16 & 17.94 to 55.48 \\
Shear force, raw & $\mathrm{SFr}$ & $\mathrm{N}$ & 753 & 35.34 & 1.19 & 17.92 to 61.81 \\
Cook loss & $\mathrm{CL}$ & $\%$ & 739 & 26.46 & 2.58 & 15.01 to 38.52 \\
Drip loss & $\mathrm{DL}$ & $\%$ & 731 & 1.72 & 0.95 & 0.06 to 5.63 \\
\hline
\end{tabular}

${ }^{1} \mathrm{~L}^{*}=$ lightness; $\mathrm{a}^{*}=$ redness; $\mathrm{b}^{*}=$ yellowness. 
doacetate/150 $\mathrm{m} M$ potassium chloride buffer. Loin ultimate $\mathrm{pH}$ ( $\mathbf{p H 2 4}$ ) was recorded at $24 \mathrm{~h}$ postmortem in $\mathrm{LM}$ at the last rib level on half-carcasses before cutting.

Intramuscular Fat Content. Total lipids were extracted according to the method outlined by Folch et al. (1957). The lipid content of fresh tissue (g/100 g) was obtained by considering DM content determined from the weight of minced LM tissues.

Glycolytic Potential. One gram of LM was homogenized into $10 \mathrm{~mL}$ of $0.55 \mathrm{M}$ perchloric acid. The glycolytic potential (GP) was then calculated according to Monin and Sellier (1985) as GP $=2$ ([glycogen] + [glucose] + [glucose-6-phosphate] $)+$ [lactate]. The GP was expressed as micromoles of lactate equivalent per gram of wet tissue.

\section{Microarray Design and Annotation}

A specific repertoire of 15,198 6mer DNA probes was set up to maximize the information content and gene coverage in analysis of pig skeletal muscle transcriptome at slaughter (Damon et al., 2011). Briefly, we used consensus contig sequences from SIGENAE pig transcript assembly (SIGENAE v8, http://www.sigenae.fr/) selected from previous analyses of LM transcriptome (Lobjois et al., 2008). Thirty-three thousand contig sequences were submitted to eARRAY online software v4.5 (Agilent Technologies, http://earray.chem.agilent. com/earray) to design one to two 60 -mer oligo probes per contig sequence (average of 1.33 probe per contig). Analysis of test LM RNA samples using all designed probes allowed for the final selection of 15,198 informative probes, while maximizing gene coverage when analyzing LM samples. Microarrays were manufactured by in situ synthesis on glass slides using an Agilent 15K (8-plex) microarray format (Agilent Technologies France, Massy, France). This repertoire was deposited in NCBI GEO online resource (http://www.ncbi.nlm. nih.gov/geo/) under reference GPL11016.

The identification of transcripts targeted by each of the 60-mer probes was conducted from probe and contig sequence homology searches using known pig transcripts (Ensembl Sscrofa9, http://www.ensembl.org/ Sus_scrofa/; NCBI Sus Scrofa RefSeq, http://www. ncbi.nlm.nih.gov/RefSeq/) or the transcriptomes of related species (Bos taurus, Equus caballus, Homo sapiens). Annotation was based on similarity and quality criteria established by Casel et al. (2009; i.e., at least 18 consecutive base pairs within 60 -mer probe sequence and $85 \%$ of homology). Overall, we validated at least 1 reference annotation for 12,939 probes (85\%) corresponding to 9,169 unique genes.

\section{RNA Extraction and Microarray Hybridization}

Ten-gram samples from the LM were collected $20 \mathrm{~min}$ after stunning and bleeding and snap frozen in liquid N.
Total RNA was extracted by crushing the frozen tissue in Trizol reagent (Invitrogen, Cergy-Pontoise, France).

Total RNA (350 ng) from each animal was labeled individually with Cy3 using the Low RNA Input Linear Amplification Kit PLUS, One-Color (ref 5188-5339, Agilent Technologies France). A single 1-color labeled sample was hybridized $\left(65^{\circ} \mathrm{C}, 17 \mathrm{~h}\right)$ per array in Agilent's SureHyb Hybridization Chambers containing $300 \mathrm{ng}$ of Cy3-labeled cRNA sample. Microarrays were scanned at $5 \mu \mathrm{m} /$ pixel resolution using the Agilent DNA Microarray Scanner G2505B, and images were analyzed with Agilent Feature Extraction Software (Version 9.5), using the GE2-v5_95_Feb07 FE extraction protocol. The raw intensities from the 15,198 probes were logtransformed and then centered within sample by subtraction of the sample median value across all probes. The microarray data have been deposited in the NCBI GEO and are accessible through GEO Series accession number GSE28714 (http://www.ncbi.nlm.nih.gov/geo/ query/acc.cgi?acc $=$ GSE28714).

\section{Functional Analysis}

The functional analysis of transcript lists of interest was undertaken by the analysis of the enrichment for specific Gene Ontology (GO) terms using the Database for Annotation, Visualization and Integrated Discovery (DAVID; Huang et al., 2009a,b) as implemented in the online software (http://david.abcc.ncifcrf.gov/). The annotated probes for both the background reference and the lists of interest were matched to their human orthologs using official human Entrez gene ID. Analyses were performed using the GO-FAT terms of DAVID. The background included 12,063 probes, representing 8,638 ortholog human genes. The functional annotation clustering of the enriched GO terms was performed with a similarity score (kappa) of 0.75 and a multiple linkage threshold of 0.50 . Cluster enrichment scores are geometrical means of $P$-values for each GO term included in the cluster and expressed on a negative logarithmic scale. Clusters were selected using enrichment score cutoffs of 1.30 and 1.10 for highly heritable transcripts and meat quality trait correlated transcripts, respectively.

\section{Genetic Parameters Estimation}

For each hybridization probe, we conducted a univariate variance analysis and independent bivariate analyses combining RNA quantification measurement with each of the meat quality traits under study. We analyzed the data with a mixed model of variance including a random polygenic effect fitted under an animal model, a fixed effect for slaughter batch, and a fixed effect for sex (intramuscular fat model). The chop weight was used as a covariate for the CL and SFc models. A fixed effect fitting hybridization batch (15 levels) was used for RNA quantification traits. A 
REML methodology was applied to estimate the variance components, corresponding genetic parameters, and their SE, using the software package ASREML 2.0 (Gilmour et al., 2006). The pedigree used to set up the animal model included 3 generation of ancestors in addition to the phenotyped animals. The meat quality phenotypes from all $\mathrm{NN} \mathrm{rn}+\mathrm{rn}+$ genotype animals of the entire $\mathrm{F}_{2}$ resource population were used in bivariate analyses when available (731 to 1,023 records per trait, as reported in Table 1). Variance component estimates were considered in the results only when model loglikelihood converged.

\section{Proportion of Heritable Transcripts}

The probability of estimating a nonzero heritability in the absence of genetic variability was determined empirically from the distribution of 3,000 estimates produced using 3,000 independent phenotype data sets of 325 records simulated without genetic variation. A false discovery rate (FDR) was calculated using the software package R/qvalue (http://cran.r-project.org/ web/packages/qvalue/index.html) according to the methodology proposed by Storey and Tibshirani (2003).

\section{RESULTS}

\section{Estimates of Heritability for RNA Quantification Abundance}

From univariate analyses, we estimated narrow sense heritability values as significantly different from zero with a FDR of $5 \%$, corresponding to a threshold of 0.051 when applied to this result set, for 9,765 probes over 15,198 probes analyzed. The median value of these significant estimates of additive genetic variation is 0.236 (the median of SE estimates is 0.211), including heritability estimates greater than 0.50 for 1,174 probes targeting 1,146 contigs. The distribution of the 9,765 significant heritability estimates is presented in Figure 1. Those 9,765 probes represent $65 \%$ of probes, 9,219 unique design contig sequences, and were annotated as products from 6,000 unique genes. We have verified that the heritability estimates presented here were not substantially correlated with either the average expression level $(\mathrm{r}=-0.11)$ or the expression level $\mathrm{SD}(\mathrm{r}=0.09)$, suggesting that our observations are not the result of a scaling effect.

\section{Biological Processes Represented in Highly Heritable LM Transcripts}

To study genes associated with highly heritable probe signals into clusters of related functional terms, a functional annotation clustering was performed with 1,174 probes, corresponding to 911 annotated transcripts that were transcribed from 843 unique genes. Nine clusters were found to be significant with an enrichment score greater than 1.30 (Table 2). The lists of genes included within each cluster are listed in supplemental file 1 (available in the online version of this paper). The highlighted GO terms show an over-representation of GO terms associated with the regulation of Rho protein signal transduction (cluster 1), the induction, regulation, and process of apoptosis (clusters 2, 4, and 8), calcium transport and metal ion binding (clusters 3 and 6 ), focal adhesion and adherent cell junctions (clusters 5 and 7 ) and glucose metabolism (cluster 9).

\section{Genetic Correlations Between RNA Concentrations and Meat Quality Traits}

Estimation of the genetic correlation $\left(\mathrm{r}_{\mathrm{G}}\right)$ between expression and meat phenotype was determined only for the 9,765 probes that showed a significant genetic variability $\left(\mathrm{h}^{2}>0.051\right)$. The limited number of animals available per molecular trait $(\mathrm{n}=325)$ makes it possible to only broadly estimate the genetic correlations between RNA concentrations and meat quality traits, with the $\mathrm{SE}$ of $\mathrm{r}_{\mathrm{G}}$ estimates ranging from a median $\mathrm{SE}$ of $0.48\left(\mathrm{a}^{*}\right)$ to a median SE of $0.60(\mathrm{pH} 45$; Table 3).

The uncertainty of those estimates is reduced for the most heritable molecular traits, ranging from a me-

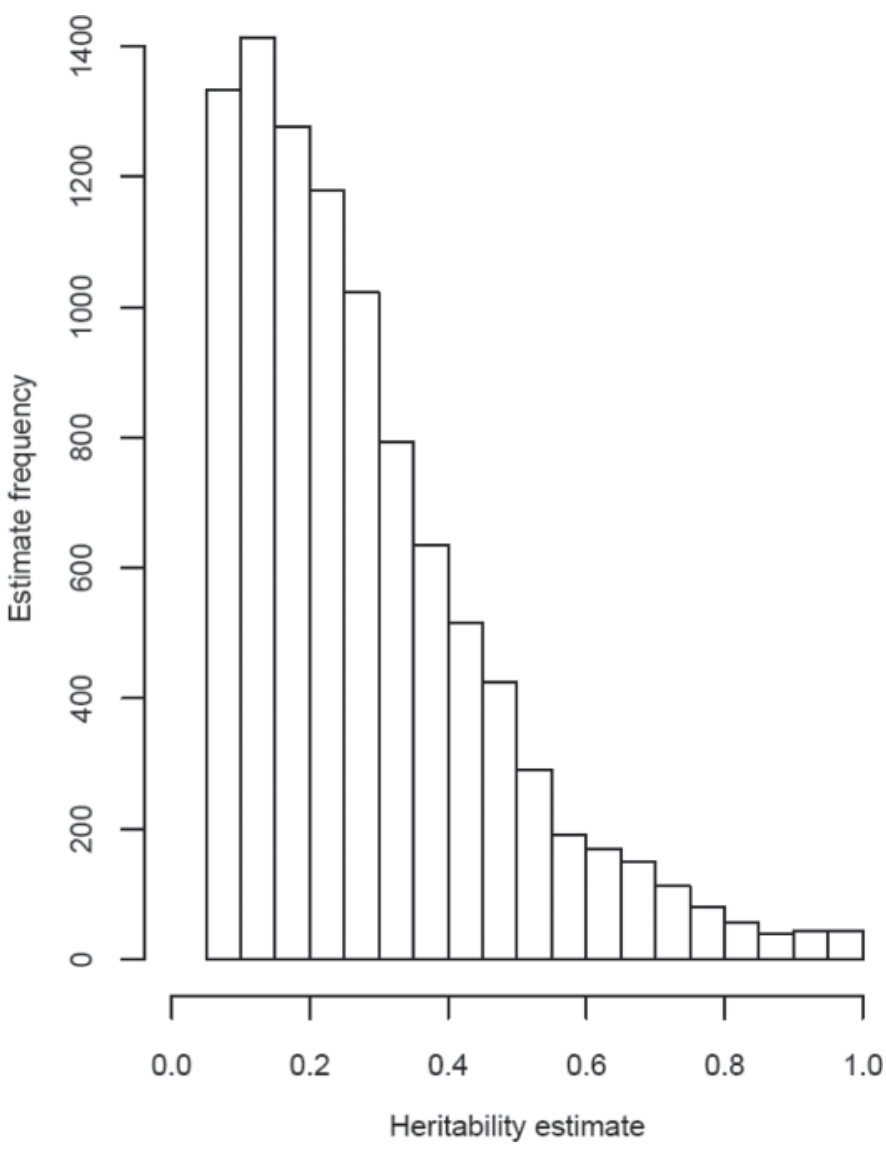

Figure 1. Distribution of heritability estimates for transcript abundance in postmortem LM, as measured using 9,765 probes $\left(\mathrm{h}^{2}>0\right.$ under a false discovery rate of $5 \%$ ). 
Table 2. Functional annotation clustering of highly heritable transcripts $\left(\mathrm{h}^{2}>0.50\right)$

\begin{tabular}{|c|c|c|c|c|c|}
\hline Cluster & $\mathrm{ES}^{1}$ & $\mathrm{n}_{\mathrm{GO}}{ }^{2}$ & Cluster-specific GO term ${ }^{3}$ & $\mathrm{n}_{\mathrm{G}}{ }^{4}$ & $P$-value ${ }^{5}$ \\
\hline 1 & 1.99 & 3 & GO:0035023 regulation of Rho protein signal transduction & 13 & 0.009 \\
\hline 2 & 1.95 & 3 & GO:0043065 positive regulation of apoptosis & 39 & 0.013 \\
\hline 4 & 1.57 & 3 & GO:0006917 induction of apoptosis & 29 & 0.037 \\
\hline 5 & 1.52 & 5 & GO:0005925 focal adhesion & 13 & 0.028 \\
\hline 6 & 1.52 & 3 & GO:0046872 metal ion binding & 203 & 0.031 \\
\hline 9 & 1.30 & 3 & GO:0006006 glucose metabolic process & 18 & 0.048 \\
\hline
\end{tabular}

${ }^{1}$ Cluster enrichment score (ES).

${ }^{2}$ Number of Gene Ontology (GO) terms $\left(\mathrm{n}_{\mathrm{GO}}\right)$ associated with this cluster.

${ }^{3}$ Identity of the lowest hierarchical level and most specific GO term.

${ }^{4}$ Number of different genes $\left(\mathrm{n}_{\mathrm{G}}\right)$ associated with the specific GO term.

${ }^{5}$ Modified Fisher's exact test $P$-value.

dian SE of $0.37\left(\mathrm{a}^{*}\right)$ to a median SE of $0.44(\mathrm{pH} 45)$, when considering only those probes where $\mathrm{h}^{2}$ in bivariate analyses is greater than 0.50 (929 to 1,509 probes, Table 3). We summarized in Table 3 the properties of the distribution of the $r_{G}$ estimates for these highly heritable transcript levels (interquartile range and median value), further restricted to the $\mathrm{r}_{\mathrm{G}}$ estimates with an SE less than 0.50 to focus on the most interpretable results. We illustrated contrasting examples of the distributions of these sets of genetic correlation estimates for 3 different traits (pH45, GP, $\mathrm{a}^{*}$ ) in Figure 2. Larger numbers of genetically correlated transcripts $\left(\left|\mathrm{r}_{\mathrm{G}}\right|>\right.$ 0.70 ) were observed for the measurements of $\mathrm{pH} 45, \mathrm{SFc}$, $\mathrm{a}^{*}$, and CL than regarding other meat quality traits. In contrast, the measurements of DL, GP, and pH24 show a substantial genetic correlation with very few muscle transcript levels.

\section{Functional Analysis of Transcripts Genetically Correlated with Meat Quality Traits}

The list of genes assigned to transcripts that were quantified as heritable traits $\left(\mathrm{h}^{2}>0.50\right)$ and were genetically correlated $\left(\left|\mathrm{r}_{\mathrm{G}}\right|>0.70\right)$ with $\mathrm{pH} 45, \mathrm{SFc}, \mathrm{a}^{*}$, and CL were characterized for functional enrichment in GO terms using the microarray repertoire as background. The clusters of GO terms enriched in the correlated gene lists for each of these 4 traits established using an enrichment scores cutoff of 1.10 are presented in Table 4. For each cluster, the most specific GO term explicit definition and the enrichment $P$-value associated with this term are shown. The lists of genes included within each cluster are listed in supplemental file 2 (available in the online version of this paper).

Table 3. Distribution and SE of genetic correlation $\left(\mathrm{r}_{\mathrm{G}}\right)$ estimates between LM transcript concentrations and meat quality traits

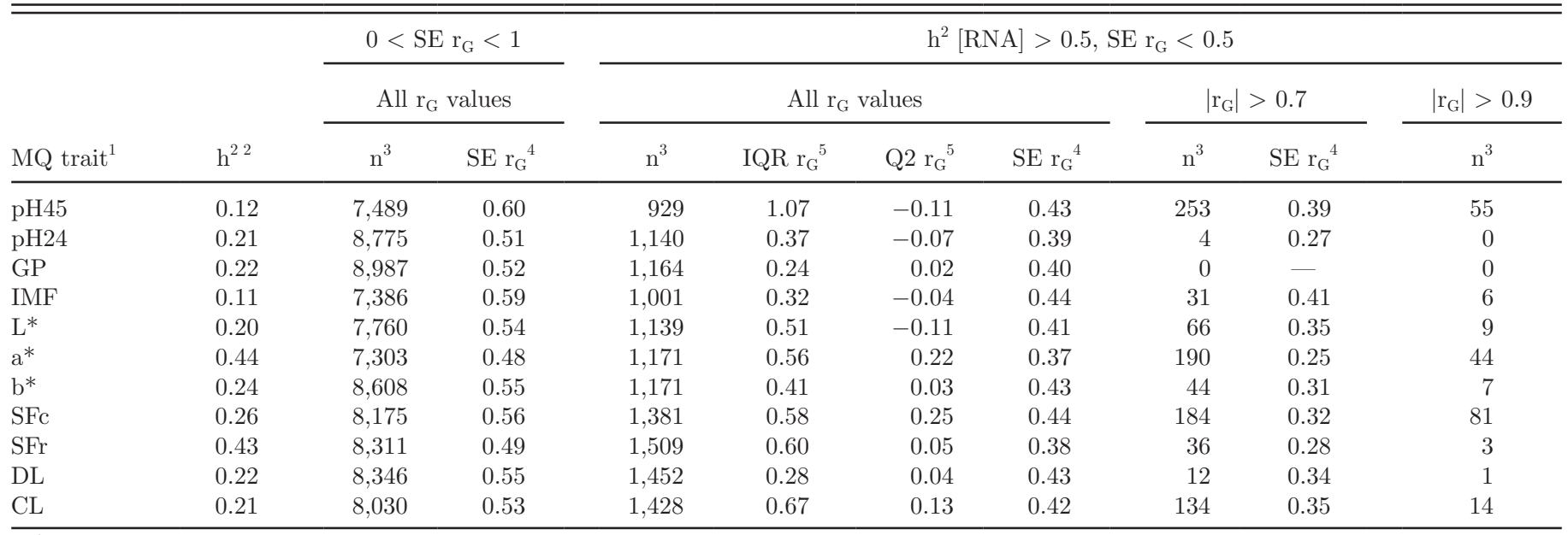

${ }^{1}$ Meat quality (MQ) traits are LM pH 45 min postmortem (pH45); loin 24-h pH (pH24); glycolytic potential (GP); intramuscular fat (IMF); loin color variables $\mathrm{L}^{*}$ (lightness), $\mathrm{a}^{*}$ (redness) and $\mathrm{b}^{*}$ (yellowness); shear force on cooked (SFc) or raw (SFr) loin; loin drip loss (DL); and loin cooking loss (CL).

${ }^{2}$ Median value of the meat quality trait heritability estimate in bivariate analyses.

${ }^{3}$ Number of probes meeting heading-specified conditions on $\mathrm{h}^{2}, \mathrm{SE} \mathrm{r}_{\mathrm{G}}$, and $\mathrm{r}_{\mathrm{G}}$, reported for all converged bivariate analyses of heritable transcripts levels.

${ }^{4}$ Median value of the genetic correlation estimates SE.

${ }^{5}$ Interquartile range (IQR) and median value (Q2) of genetic correlation estimates $\left(\mathrm{r}_{\mathrm{G}}\right)$ distribution. 

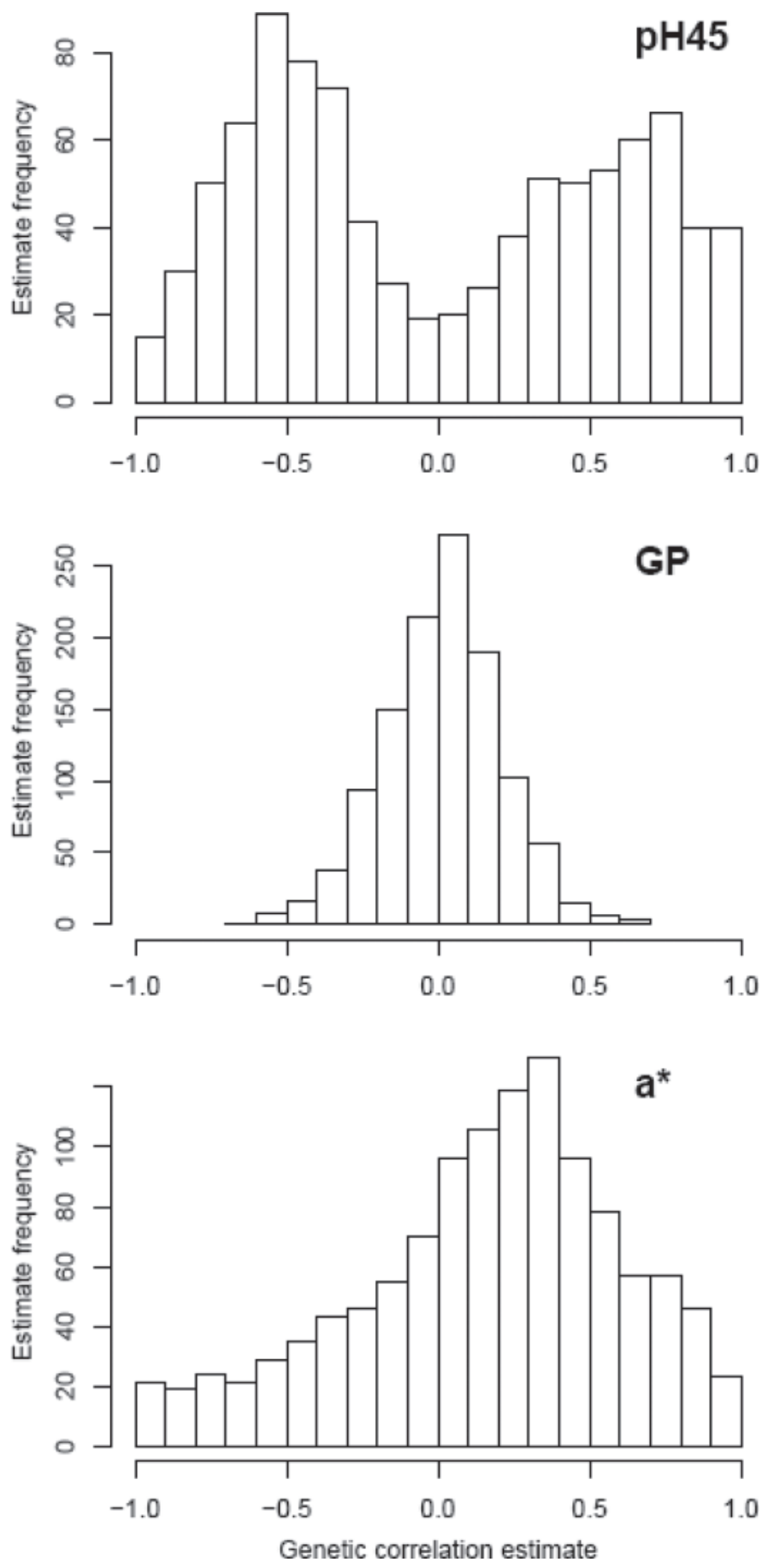

Figure 2. Distribution of genetic correlation estimates between heritable transcripts $\left(\mathrm{h}^{2}>0.50, \mathrm{SE}_{\mathrm{G}}<0.50\right)$ and LM pH $45 \mathrm{~min}$ postmortem ( $\mathrm{pH} 45)$, LM glycolytic potential (GP), and loin color redness $\left(a^{*}\right) \cdot r_{G}=$ genetic correlation.

For CL, 3 clusters highlight the genetic variability of transcripts involved in the induction of apoptosis and regulation of fatty acid oxidation. Transcript levels from genes known to be involved in complement activation and protein polymerization were observed as genetically correlated with SFc. The clusters associated with transcripts genetically correlated with $a^{*}$ are focused on glucose metabolism and neoglucogenesis. The transcripts that are genetically correlated with
pH45 highlight 2-cell compartments, the lumen of intracellular organelles and the membrane of cytoplasmic vesicles, whereas the voltage-dependent cation channel activity is highlighted as a biological process.

\section{DISCUSSION}

\section{Genetic Variability of Transcript Abundance in Pig Postmortem LM}

Our results document that $65 \%$ of the postmortem LM RNA concentration measurements, as assayed by hybridization on a muscle-specific array, are genetically determined because essentially all probes were informative (Damon et al., 2011). The limited number of full- and half-sib families included in this experimental population may generate a sampling variance in estimates. Nonetheless, the SE of the heritability estimates for these molecular traits do support our interpretation of the actual genetic variability of LM transcriptome, even if the individual transcript heritability values were only broadly assessed.

The observed genetic variability in LM transcript concentration is consistent with other reports of genetic variability in transcript abundance in a variety of organisms. Studies in yeast have shown that more than $60 \%$ of the transcripts whose abundance was measured in segregating populations could be characterized with heritabilities greater than 0.69 (Brem and Kruglyak, 2005). The available data from human tissues show that the relative concentrations of respectively 59 and $71 \%$ of transcripts, as measured in total blood or adipose tissue respectively, are significantly heritable, with an average heritability estimate of 0.30 for those heritable transcripts (Emilsson et al., 2008). Data from studies performed in mice document a median value of 0.14 for heritability estimated among all of the possible transcripts quantification levels measured in adipose tissues (Petretto et al., 2006).

\section{Functional Interpretation of Transcriptome Genetic Variability}

Apoptosis induction has been proposed as an essential mechanism involved in the transformation of muscle in meat, contributing to the tenderization of meat through an early triggering activity of caspases (Herrera-Mendez et al., 2006; Ouali et al., 2006). Variations in the regulation of apoptosis have been further suggested as an underlying cause of differential tenderness in bovine meat by the observation of differences in the concentrations of proteins from the inner mitochondrial membranes of muscle samples taken as early as $10 \mathrm{~min}$ postexsanguination (Laville et al., 2009). Therefore, the observation of large individual and genetic variation in the induction of the apoptosis processes in postmortem LM samples can be seen as a consequence of the exsanguination-induced muscle ischemia. The selection of a muscle sampling point at $20 \mathrm{~min}$ after stunning 
Table 4. Functional analysis of heritable transcripts that were genetically correlated with meat quality traits

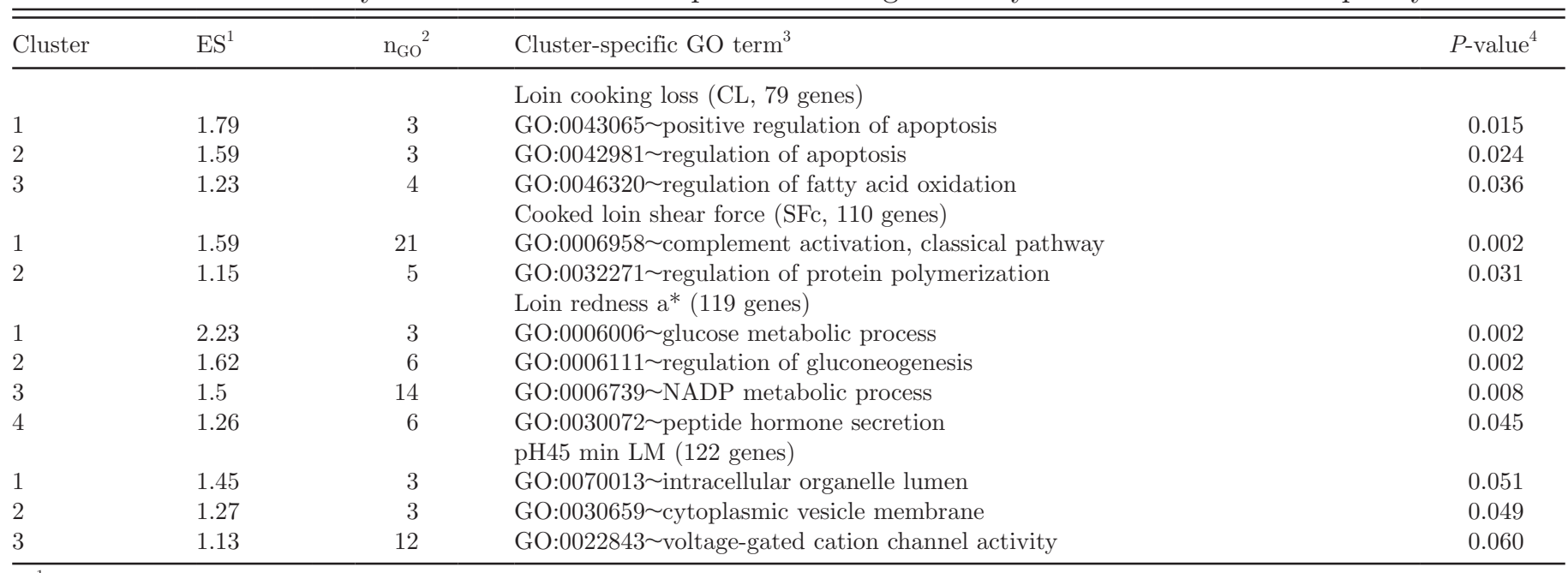

${ }^{1}$ Cluster enrichment score (ES).

${ }^{2}$ Number of different Gene Ontology (GO) terms associated with this cluster.

${ }^{3}$ Identity of the lowest hierarchical level and most specific GO term. NADP $=$ NAD phosphate.

${ }^{4}$ Modified Fisher's exact test $P$-value.

may have highlighted individual variation in the early and unbuffered response to a sudden challenge.

\section{Proportion of Transcripts Genetically Correlated with Meat Quality Traits}

The genetic correlation between 2 traits is thought to reflect either genetic linkage between loci affecting each trait or pleiotropic effects of the same loci on both traits. Our population design maximizes long-range genetic linkage effects in the $\mathrm{F}_{2}$ generation. Therefore, this mechanism may have substantially inflated some of our estimates of the genetic correlations between molecular and meat quality traits in this population. The accuracy of the genetic correlation estimates proved to be severely limiting for interpretation because of the limited size of our data set. However, we propose a cautious interpretation of the entire distribution of the genetic correlations estimates for each meat quality trait that we restricted to the most heritable RNA concentrations.

The large differences we observed between the distributions of the genetic correlation estimates among the different meat quality traits was not expected, considering the genome-wide relevance of the repertoire of probes used and the existence of genetic variability in all of the meat quality traits studied. A naïve assumption may have been to identify, among the large number of heritable transcripts, some transcripts that would be genetically correlated with each of the meat quality traits. This would be expected if postmortem muscle transcriptome was patterning the whole muscle physiology. In this respect, the lack of RNA species showing substantial genetic correlations with the meat pH24 and the glycolytic potential (traits nonetheless determined by a sizable genetic variation, $\mathrm{h}^{2}$ of GP $=$ 0.22 ) brings into question the dynamics of phenotype construction and the persistence of its footprint on gene expression profiles over time. To explain this observation, one may simply hypothesize that the expression of genes involved in the genetic control of muscle glycogen stores depletion and recovery during antemortem period does not persist, or at least does not dominate the patterns of postmortem gene expression that we analyzed. But this hypothesis does not account for the extent of our observation that all of the genes contributing to the control of glycogen storage and mobilization are well represented in the array used for transcriptome analysis, are transcribed in LM postmortem, and some even showed substantial genetic variation in LM mRNA content (as those reported for their genetic correlation with meat redness a*). An alternative hypothesis, therefore, would be that the gene expression levels are essentially constrained by homeostatic regulatory mechanisms, which over time are buffering all sources of variation, including the genetic variability, in this case between the antemortem and postmortem time points. Gene expression buffering has been recognized as an essential control mechanism to dampen the consequences of transcription noise (Fraser et al., 2004; Raser and O'Shea, 2004) and proposed as an essential function of microRNA (Wu et al., 2009). This latter hypothesis would support a relative independence between the genetic variability of antemortem muscle transcription (the genome expression profile that one may suppose is responsible for mediating or accompanying variation in the control of antemortem glycogen stores) and the genetic variability of postmortem transcription profiles that we evaluated in this work, reflecting muscle reaction to ischemia. Finally, this independence would support the observed disconnection between the genetic variability of the muscle glycolytic potential or the ultimate $\mathrm{pH}$, and the genetic variability of postmortem transcript abundance. 
We observed that the genetic variability of the postmortem LM transcriptome is linked with the genetic variability of a postmortem muscle physiology measurement ( $\mathrm{pH} 45)$ and distantly assessed measurements of meat color $\left(\mathrm{a}^{*}\right)$ and loin cooking (SFc, CL). The transcription profiles may subsequently better reflect muscle physiology contemporary of the RNA sampling point, beside its translation into remote consequences that affect meat consumption. A recent study reported significant phenotypic associations between postmortem LM transcriptome analysis and loin color redness a* (Te Pas et al., 2010). Our data suggest that the associations reported by these authors may result from a genetic determinism with pleiotropic consequences on the transcriptome and loin redness.

\section{Functional Interpretation of Transcripts Genetically Correlated with Meat Quality Traits}

Cooking Loss. The functional analysis of transcripts that show a substantial genetic correlation with loin cooking losses highlights apoptosis as an overrepresented cell function in this group of genes. The first steps of apoptosis involve the condensation of the cytoplasm, cell shrinking, and result in the expansion of extracellular space (Bortner and Cidlowski, 2007). The genetic correlations that we observed may thus result from a genetic variability that drives the dynamics of apoptosis induction postmortem and subsequently affects the water-holding capacity of meat during cooking.

Cooked Loin Shear Force. Complement activation has been described as an essential component of skeletal muscle ischemia-reperfusion injury (Weiser et al., 1996) that is thought to be mediated through the action of membrane-complement attack complexes (Kyriakides et al., 1999). More specifically, the identified transcripts of $\mathrm{C} 1 \mathrm{~S}$ and $\mathrm{C} 1 \mathrm{R}$ complement subunits are encoding essential proteases of this complex (Davis et al., 2008), and genetic correlation of their expression levels with meat shear force would be consistent with the role generally accepted for postmortem proteases activity in meat tenderness variation in pigs (Melody et al., 2004).

Loin Color $\boldsymbol{a}^{*}$. Loin color redness principally results from oxymyoglobin concentration and oxidative status (Gorelik and Kanner, 2001). We identified the transcript concentration of glycolysis enzymes as genetically correlated with loin color redness $a^{*}$, which suggests that the regulation of glycolysis kinetics or its extent may drive the muscle oxidative capacity with regard to oxymyoglobin.

$p$ H45. The voltage-gated cation channel activity and cation channel complex cell component point to the excitation-contraction coupling mechanism, which operates through the release of free $\mathrm{Ca}^{2+}$ from sarcoplasmic reticulum stores. Contraction mobilizes the available energy and results in increased glycolysis in the case of hypoxic tissues, leading to acidosis where resulting pyruvate is metabolized into lactate. The RYR1 mutation (Fujii et al., 1991) does constitute, by itself, an example of genetic variability with documented pleiotropic effects on both calcium channel activity in skeletal muscle and pH45 (Larzul et al., 1997; Sellier, 1998). However, the genetic variability observed here in $\mathrm{pH} 45$ and transcription is independent of the RYR1 polymorphism because the animals used in the present study were not carrying the RYR1 mutated allele (see methods). This observation illustrates that the same set of functions can be affected by different polymorphisms leading to similar effects, and that the genetic variability for the pH45 trait in a HAL NN (wild-type) population could be mediated nonetheless through similar biological pathways as those affected by the RYR1 mutation. Malignant hyperthermia susceptibility (MHS) is a genetic condition in human and pig resulting from the same or additional mutations in the RYR1 gene (Fujii et al., 1991; Manning et al., 1998). Malignant hyperthermia susceptibility in humans can also result from a mutation in the $\alpha$ 1S subunit of the voltage-gated calcium channel CACNA1S (Monnier et al., 1997). We identified as genetically correlated with $\mathrm{pH} 45$, the LM concentration of the CACNA1A and CACNA1G transcripts, encoding 2 paralogs of CACNA1S.

\section{Use of RNA Measurements for Genetic Improvement of Meat Quality}

Alternative selection criteria are to be considered relative to their heritability and genetic correlation with traits belonging to breeding goals. For measurements taken on the same set of animals relative to selection candidates, an alternative selection criteria with an heritability $\mathrm{h}^{\prime 2}$ and a genetic correlation $\mathrm{r}_{\mathrm{G}}$ with a selected trait of heritability $h^{2}$ would have to verify $r_{G}$ ${ }^{*} \mathrm{~h}^{\prime}>\mathrm{h}$ to support a potential benefit in increased accuracy of breeding value estimation (Searle, 1965). In the case of selection for improvement of a meat quality trait with a typical heritability of 0.25 , an illustration of a competitive alternative selection criterion could be the quantification of a specific RNA species in a given tissue sample associated with an heritability of at least 0.50 and a genetic correlation of at least 0.70 with the selected meat quality trait. These conditions are met by a large number of LM transcript levels for $\mathrm{pH} 45$, $\mathrm{a}^{*}, \mathrm{SFc}$, and CL. These traits would therefore be candidates for the application of indirect selection strategies based on measurements of RNA concentrations in postmortem LM.

A substantial improvement in the accuracy of breeding values estimation may be at hand if informative RNA species such as those identified in this work for selected meat quality traits could be measured in skeletal muscle from selection candidates themselves. Compared with the measurements of the same trait in 
relatives, measurements on selection candidates would allow an improvement in the selection response by $50 \%$ when compared with the systematic measurement of 2 full-sibs, or $100 \%$ when compared with the systematic measurement of 4 half-sibs, for a typical meat quality trait with a heritability of 0.25 . Improvement in the selection response would result from increased accuracy of breeding values estimated from an animal itself vs. phenotypes of relatives (Falconer and Mackay, 1996).

Taken together, our data support the likelihood of heritable LM transcripts that are genetically correlated with some of the pig meat quality traits. It would be of significant practical interest for applications in breeding programs to re-estimate these genetic parameters using RNA quantification measurements acquired from in vivo-sampled muscles.

\section{LITERATURE CITED}

Bortner, C. D., and J. A. Cidlowski. 2007. Cell shrinkage and monovalent cation fluxes: Role in apoptosis. Arch. Biochem. Biophys. $462: 176-188$.

Brem, R. B., and L. Kruglyak. 2005. The landscape of genetic complexity across 5,700 gene expression traits in yeast. Proc. Natl. Acad. Sci. USA 102:1572-1577.

Casel, P., F. Moreews, S. Lagarrigue, and C. Klopp. 2009. SigReannot: An oligo-set re-annotation pipeline of Ensembl transcripts and Unigene clusters. BMC Proc. 3(Suppl. 4):S3.

Damon, M., F. Herault, A. Vincent, Le Roy P., and P. Cherel. 2011. Characterization of a pig skeletal muscle microarray to study pork quality: The GenmascqChip 15K. Nature Precedings 10.1038/npre.2011.5730.1

Davis, A. E., III, P. Mejia, and F. Lu. 2008. Biological activities of C1 inhibitor. Mol. Immunol. 45:4057-4063.

Davoli, R., and S. Braglia. 2007. Molecular approaches in pig breeding to improve meat quality. Brief Funct. Genomic Proteomic 6:313-321.

Emilsson, V., G. Thorleifsson, B. Zhang, A. S. Leonardson, F. Zink, J. Zhu, S. Carlson, A. Helgason, G. B. Walters, S. Gunnarsdottir, M. Mouy, V. Steinthorsdottir, G. H. Eiriksdottir, G. Bjornsdottir, I. Reynisdottir, D. Gudbjartsson, A. Helgadottir, A. Jonasdottir, A. Jonasdottir, U. Styrkarsdottir, S. Gretarsdottir, K. P. Magnusson, H. Stefansson, R. Fossdal, K. Kristjansson, H. G. Gislason, T. Stefansson, B. G. Leifsson, U. Thorsteinsdottir, J. R. Lamb, J. R. Gulcher, M. L. Reitman, A. Kong, E. E. Schadt, and K. Stefansson. 2008. Genetics of gene expression and its effect on disease. Nature 452:423-428.

Falconer, D. S., and T. F. C. Mackay. 1996. Selection: III. Information from relatives. Pages 228-246 in Introduction to Quantitative Genetics. Addison Wesley Longman Limited, Harlow, UK.

Folch, J., M. Lees, and G. H. S. Stanley. 1957. A simple method for the isolation and purification of total lipides from animal tissues. J. Biol. Chem. 226:497-509.

Fraser, H. B., A. E. Hirsh, G. Giaever, J. Kumm, and M. B. Eisen. 2004. Noise minimization in eukaryotic gene expression. PLoS Biol. 2:e137.

Fujii, J., K. Otsu, F. Zorzato, S. de Leon, V. K. Khanna, J. E. Weiler, P. J. O'Brien, and D. H. MacLennan. 1991. Identification of a mutation in porcine ryanodine receptor associated with malignant hyperthermia. Science 253:448-451.

Gilmour, A. R., B. J. Gogel, B. R. Cullis, and R. Thompson. 2006. ASReml User Guide Reference 2.0. VSN Int. Ltd., Hemel Hempstead, UK.

Gorelik, S., and J. Kanner. 2001. Oxymyoglobin oxidation and membrane lipid peroxidation initiated by iron redox cycle: Preven- tion of oxidation by enzymic and nonenzymic antioxidants. J. Agric. Food Chem. 49:5945-5950.

Herrera-Mendez, C. H., S. Becila, A. Boudjellal, and A. Ouali. 2006. Meat ageing: Reconsideration of the current concept. Trends Food Sci. Technol. 17:394-405.

Huang, W., B. T. Sherman, and R. A. Lempicki. 2009a. Bioinformatics enrichment tools: Paths toward the comprehensive functional analysis of large gene lists. Nucleic Acids Res. 37:1-13.

Huang, W., B. T. Sherman, and R. A. Lempicki. 2009b. Systematic and integrative analysis of large gene lists using DAVID bioinformatics resources. Nat. Protoc. 4:44-57.

Kyriakides, C., W. Austen Jr., Y. Wang, J. Favuzza, L. Kobzik, F. D. Moore Jr., and H. B. Hechtman. 1999. Skeletal muscle reperfusion injury is mediated by neutrophils and the complement membrane attack complex. Am. J. Physiol. 277:C1263-C1268.

Larzul, C., R. P. Le, R. Gueblez, A. Talmant, J. Gogue, and P. Sellier. 1997. Effect of the halothane genotype (NN,Nn,nn) on growth, carcass and meat quality traits of pigs slaughtered at 95 $\mathrm{kg}$ or $125 \mathrm{~kg}$ live weight. J. Anim. Breed. Genet. 114:309-320.

Laville, E., T. Sayd, M. Morzel, S. Blinet, C. Chambon, J. Lepetit, G. Renand, and J. F. Hocquette. 2009. Proteome changes during meat aging in tough and tender beef suggest the importance of apoptosis and protein solubility for beef aging and tenderization. J. Agric. Food Chem. 57:10755-10764.

Laville, E., T. Sayd, C. Terlouw, C. Chambon, M. Damon, C. Larzul, P. Leroy, J. Glenisson, and P. Cherel. 2007. Comparison of sarcoplasmic proteomes between two groups of pig muscles selected for shear force of cooked meat. J. Agric. Food Chem. $55: 5834-5841$.

Lobjois, V., L. Liaubet, M. SanCristobal, J. Glenisson, K. Feve, J. Rallieres, R. P. Le, D. Milan, P. Cherel, and F. Hatey. 2008. A muscle transcriptome analysis identifies positional candidate genes for a complex trait in pig. Anim. Genet. 39:147-162.

Manning, B. M., K. A. Quane, H. Ording, A. Urwyler, V. Tegazzin, M. Lehane, J. O'Halloran, E. Hartung, L. M. Giblin, P. J. Lynch, P. Vaughan, K. Censier, D. Bendixen, G. Comi, L. Heytens, K. Monsieurs, T. Fagerlund, W. Wolz, J. J. Heffron, C. R. Muller, and T. V. McCarthy. 1998. Identification of novel mutations in the ryanodine-receptor gene (RYR1) in malignant hyperthermia: genotype-phenotype correlation. Am. J. Hum. Genet. 62:599-609.

Melody, J. L., S. M. Lonergan, L. J. Rowe, T. W. Huiatt, M. S. Mayes, and E. Huff-Lonergan. 2004. Early postmortem biochemical factors influence tenderness and water-holding capacity of three porcine muscles. J. Anim. Sci. 82:1195-1205.

Milan, D., J. T. Jeon, C. Looft, V. Amarger, A. Robic, M. Thelander, C. Rogel-Gaillard, S. Paul, N. Iannuccelli, L. Rask, H. Ronne, K. Lundstrom, N. Reinsch, J. Gellin, E. Kalm, P. L. Roy, P. Chardon, and L. Andersson. 2000. A mutation in PRKAG3 associated with excess glycogen content in pig skeletal muscle. Science 288:1248-1251.

Monin, G., and P. Sellier. 1985. Pork of low technological quality with a normal rate of muscle $\mathrm{pH}$ fall in the immediate postmortem period: The case of the Hampshire breed. Meat Sci. 13:49-63.

Monnier, N., V. Procaccio, P. Stieglitz, and J. Lunardi. 1997. Malignant-hyperthermia susceptibility is associated with a mutation of the alpha 1-subunit of the human dihydropyridine-sensitive L-type voltage-dependent calcium-channel receptor in skeletal muscle. Am. J. Hum. Genet. 60:1316-1325.

Otsu, K., M. S. Phillips, V. K. Khanna, S. de Leon, and D. H. MacLennan. 1992. Refinement of diagnostic assays for a probable causal mutation for porcine and human malignant hyperthermia. Genomics 13:835-837.

Ouali, A., C. H. Herrera-Mendez, G. Coulis, S. Becila, A. Boudjellal, L. Aubry, and M. A. Sentandreu. 2006. Revisiting the conversion of muscle into meat and the underlying mechanisms. Meat Sci. $74: 44-58$.

Petretto, E., J. Mangion, N. J. Dickens, S. A. Cook, M. K. Kumaran, H. Lu, J. Fischer, H. Maatz, V. Kren, M. Pravenec, N. 
Hubner, and T. J. Aitman. 2006. Heritability and tissue specificity of expression quantitative trait loci. PLoS Genet. 2:e172.

Ponsuksili, S., E. Murani, C. Phatsara, E. Jonas, C. Walz, M. Schwerin, K. Schellander, and K. Wimmers. 2008. Expression profiling of muscle reveals transcripts differentially expressed in muscle that affect water-holding capacity of pork. J. Agric. Food Chem. 56:10311-10317.

Raser, J. M., and E. K. O'Shea. 2004. Control of stochasticity in eukaryotic gene expression. Science 304:1811-1814.

Searle, S. R. 1965. The value of indirect selection: I. Mass selection. Biometrics 21:682-707.

Sellier, P. 1998. Genetics of meat and carcass traits. Pages 436-510 in The Genetics of the Pig. M. Rothschild and A. Ruvinsky, ed. CABI Int.

Storey, J. D., and R. Tibshirani. 2003. Statistical significance for genomewide studies. Proc. Natl. Acad. Sci. USA 100:9440-9445.

Te Pas, M. F., E. Keuning, B. Hulsegge, A. H. Hoving-Bolink, G. Evans, and H. A. Mulder. 2010. Longissimus muscle transcrip- tome profiles related to carcass and meat quality traits in fresh meat Pietrain carcasses. J. Anim. Sci. 88:4044-4055.

Weiser, M. R., J. P. Williams, F. D. Moore Jr., L. Kobzik, M. Ma, H. B. Hechtman, and M. C. Carroll. 1996. Reperfusion injury of ischemic skeletal muscle is mediated by natural antibody and complement. J. Exp. Med. 183:2343-2348.

Wimmers, K., E. Murani, M. F. Te Pas, K. C. Chang, R. Davoli, J. W. Merks, H. Henne, M. Muraniova, N. da Costa, B. Harlizius, K. Schellander, I. Boll, S. Braglia, A. A. de Wit, M. Cagnazzo, L. Fontanesi, D. Prins, and S. Ponsuksili. 2007. Associations of functional candidate genes derived from gene-expression profiles of prenatal porcine muscle tissue with meat quality and muscle deposition. Anim. Genet. 38:474-484.

Wu, C. I., Y. Shen, and T. Tang. 2009. Evolution under canalization and the dual roles of microRNAs: A hypothesis. Genome Res. 19:734-743. 
Supplementary Material

References

Citations
Supplementary material can be found at: http://www.journalofanimalscience.org/content/suppl/2012/02/17/jas.2011 $-4198 . \mathrm{DC} 1 . \mathrm{html}$

This article cites 34 articles, 12 of which you can access for free at: http://www.journalofanimalscience.org/content/90/3/699\#BIBL

This article has been cited by 2 HighWire-hosted articles:

http://www.journalofanimalscience.org/content/90/3/699\#otherarticles 